\title{
The state of modern heat power engineering and increasing the economic efficiency of heat supply
}

Tatiana Kharlamova $^{1, *}$, and Ksenia Osipova ${ }^{1}$

${ }^{1}$ Peter the Great St. Petersburg Polytechnic University, 195251 Polytechnicheskaya str., 29, Russia

\begin{abstract}
Annotation. The article analyzes the current state of the Russian heat power engineering and identifies the main problems in its economic development. From the position of an integrated approach, the problems of the Russian heat supply system are divided into three categories: technological, economic and social. The using electricity for the needs of heat supply is determined as an effective way of solution these problems. In this context the electric heat supply is offered as an alternative to the modern heat supply system. The article identifies the main factors of electric heating, showing its economic advantages over other types of heat supply systems. On this basis the authors justify the prospects of electric heating system from the point of view of economic development of the Fuel Energy Complex and the national economy as a whole.
\end{abstract}

\section{Introduction}

The Russian Federation is the largest player in the world energy resources market. The country has more than $12 \%$ of the world's oil reserves [1], $25 \%$ of natural gas (Russia ranks first among all countries) and $17 \%$ of coal reserves. Totally it makes about a third of all energy resources of the planet. Russia also holds a leading position in annual production and export of energy resources. Annually our country produces about 547.6 million tons of oil (12\% of the global production), of which 50\% (about 254.812 million tons) are exported [2]. No country in the world has such relative indicators of energy resources exports [3, 4]. It is obvious, that the Russian Fuel Energy Complex is the foundation of the national economy of the country determining its place in a global economy.

A significant part of the Fuel Energy Complex belongs to the heat supply system. The issues related to the economic efficiency of the heat supply system are becoming more acute every year. But the proposed solutions in this sphere are often unfeasible in the current conditions. At the same time the heat supply system, as an important part of the Fuel Energy Complex responsible for the energy security and well-being of the national economy, needs to change [5]. We suppose that the electric heat supply will compete with the traditional heating system in the nearest future. In the studies of some modern scientists $[6,7,8]$ the electric heat supply is offered as an alternative to the existing system. These studies form the basis for further research in this field and raise the issue of the electric heat supply prospects in Russia. From the positions of economic efficiency the concept of electric heat supply is considered as a mechanism for improving the energy and environmental safety of our country. It underlines the necessity for the further research in the field of the electric heat supply and its economic efficiency.

The purpose of this article is to assess the current state of the Russian heat power engineering and develop alternative ways to solve existing problems. To achieve this goal, the tasks are following:

1. To analyze the current state and identify the problems in a sphere of efficiency of the Russian heat supply system;

2. To justify the proposals for the development of the heat supply system on the basis of electric heat supply.

\section{Methods}

The Russian heat supply system is the biggest in the world. It combines different technologies and heating systems on the centralized basis. $70 \%$ of all heat energy in the country is produced by such method. The scale of this system has no analogues in the world. For a comprehensive assessment of the heat power engineering, all indicators will be given in unified units. Thus, the data on the installed capacity (electric and thermal) will be given in gigawatts (GW) and the production of the thermal energy and electricity - in terawatt-hours (TWh).

Currently, the country produces about $1555 \mathrm{TW}$ of thermal energy per year, which corresponds to operating capacities of $1002 \mathrm{GW}$. For comparison, the annual electricity output is $1070 \mathrm{TW}$, which corresponds to the operating capacity of $236 \mathrm{GW}$ [2]. So Russia produces almost one and a half times more thermal energy than electricity.

Table 1 represents the structure of the heat energy production and installed heat capacity. More than half of the centralized heat $(54 \%)$ is produced by boiler-houses, which are more than 70000 at the country. Another part of the heat energy is generated by thermal power plants, which are more than 500 in the country.

Table 1. The structure of the heat energy production in Russia, 2016

\begin{tabular}{|l|c|c|}
\hline \multirow{2}{*}{} & \multicolumn{2}{|c|}{ The heat energy production } \\
\cline { 2 - 3 } & TWh & $\%$ \\
\hline In total & 1555 & 100 \\
\hline Boiler-houses & 836 & 54 \\
\hline
\end{tabular}

\footnotetext{
${ }^{*}$ Corresponding author: Kharlamova_t@list.ru
} 


\begin{tabular}{|l|c|c|}
\hline Thermal power plants & 712 & 45 \\
\hline Other & 7 & $<1$ \\
\hline
\end{tabular}

Decentralized (autonomous) heat supply produces $30 \%$ of the heat energy in Russia. One third of this production falls on boilers, and the rest - on various autonomous heat generators. The population and institutions of the social sphere consume almost half of the heat of district heating [9]. Industry consumes approximately the same amount of the heat energy (Table 2). Transport and construction sector follow then. Thus, industry and population are the main consumers of the heat energy from district heating systems.

Table 2. The structure of heat energy consumption in Russia, average data 2012-2016

\begin{tabular}{|l|c|c|}
\hline \multirow{2}{*}{} & \multicolumn{2}{|c|}{ The heat energy production } \\
\cline { 2 - 3 } & TWh & $\%$ \\
\hline In total & 1555 & 100 \\
\hline Industry & 669 & 43 \\
\hline Population & 638 & 41 \\
\hline $\begin{array}{l}\text { Other (construction } \\
\text { sector, transport etc.) }\end{array}$ & 248 & 16 \\
\hline
\end{tabular}

An essential feature of the existing heat supply system is the lack of flexible regulation the volumes of necessary, consumed and produced heat. It concerns the technical, organizational and economic aspects. For example, there is the common situation when a consumer needs 100 units heat, but receives 150 and pays for 300 units.

The main reason for this situation is the nature of the thermal energy which is difficult to store, transfer and account. Another reason is connected with technical imperfection of the existing district heating system.

The state of generating equipment and heat networks is critical now [10]. According to the Ministry of Energy, the Russian district heating system has a significant oversupply of generating capacity. The condition of generating equipment is disastrous - the average age of heat power plants is about 31 years (only $25 \%$ of power boilers and $36 \%$ of turbines of thermal power plants are younger than 30 years) [11]. There is a high rate of fuel burnout: 37 million tons (of fuel equivalents) per year. In addition, a significant part of the thermal power plants operates in a condensation mode, which is much less efficient than the cogeneration one. It means that thermal power plants play the role of boilers $[12,13]$.

A similar situation occurs with heat networks. Today most of the heating pipelines (up to 80\%) need to be replaced and overhauled. The losses of heat during transmission over networks often exceed $30 \%$. Due to the high accident rate of heating pipelines, their maintenance entails high costs. The accident rate of pipelines with maximum diameters is approximately 1 case per kilometer per year, and pipelines with a diameter of 0.2 meters and less -3 cases [14]. For comparison, in Finland the heat transmission losses are three times less.

Large losses are accompanied not only by the stages of production and transmission of thermal energy, but also the stage of its consumption. There are situations of excessive supply of thermal energy to the consumer in a warm season and insufficient supply in cold (without the possibility of regulation in houses by the consumer). That increases the demand for electricity for heating. Besides, more than half of the buildings connected to the district heating system are not equipped with devices for recording heat consumption. Most buildings haven't devices for regulating the volume of heat supplied. It entails two serious problems:

1. Impossibility of drawing up a balance of production and consumption of thermal energy. The volumes of the consumed thermal energy are calculated by standards now. Consequently, the consumer pays for the whole amount of energy released by power plants and boiler houses, taking into account the losses [15]. Moreover, the energy losses are quite significant.

2. Lack of motivation to energy saving among consumers. As a rule the consumer isn't interested in saving energy because eventually he pays for all received thermal energy, regardless of how much energy it was consumed or saved.

It should be noted, that even if the consumer is equipped with heat recording and regulating devices, and accordingly, he cares about the less consumption, the savings are still relative[16]. The savings are reflected in the consumer, but the efficiency of the whole heat supply cycle is not affected. This is explained by the construction of a modern heat supply cycle, which uses water (or steam) as the main heat transfer agent. Such energy (unlike electricity) cannot be accumulated or quickly redirected to other objects. It means that even if the consumer saved energy through self-regulation in the building, this energy just goes to the atmosphere without redirection for other needs.

Energy saving is the most important reference point of the national economy [17]. This problem requires not only a technological reorientation of the existing heat supply system, but also significant changes in consumer behavior as well as in investment policy [18]. The expected results of its solution will be connected with a positive influence on energy efficiency and economic efficiency of the national economy of Russia.

\section{Results and Discussion}

All of the above allows dividing the problems of the Russian heat supply system into three categories (Table 3). 
Table 3. The classification of the problems of the modern domestic heat supply system

\begin{tabular}{|l|l|}
\hline \multicolumn{1}{|c|}{ Type of problems } & \multicolumn{1}{c|}{ Characteristic of problems } \\
\hline Technological problems & $\begin{array}{l}\text { High degree of the moral and technical deterioration of generating equipment; } \\
\text { Large energy losses at the heat pipelines; } \\
\text { Insufficient equipment of consumers with heat recording and regulating devices }\end{array}$ \\
\hline $\begin{array}{l}\text { Economic and management } \\
\text { problems }\end{array}$ & $\begin{array}{l}\text { Inconsistency of the heat supply cycle stages; } \\
\text { Absence of an effective mechanism of the heat supply management; } \\
\text { Contradictions in the interests of the heat supply system participants; } \\
\text { Separation of the energy market into the electric energy market and the heat energy } \\
\text { market; } \\
\text { Monopolization of the heat supply system }\end{array}$ \\
\hline Social problems & $\begin{array}{l}\text { Lack of motivation to energy saving among consumers; } \\
\text { Low culture of energy consumption and energy saving }\end{array}$ \\
\hline
\end{tabular}

It is obvious that the solution of these problems requires an integrated approach. The domestic heat supply requires a thorough review and reorientation of the whole system of government regulation [19]. We suppose that in the nearest future the electric heat supply can compete with the traditional cogeneration system. Moreover, the factors that determine the prospects for using electricity for the needs of heat supply can serve as a solution to many economic problems.

We highlight the main factors of electric heating, showing its advantages over other types of heat supply (centralized and autonomous). This justifies the prospects of implementation such type of the heat power engineering both in the modern world and Russia:

a) Flexibility. Electricity as the main transmitter of energy in electric heat supply can be produced from any kind of primary energy, including renewable energy resources. Heat supply cycle based on electricity will flexibly adapt to the changing energy market and to any new energy production technologies.

b) Controllability. Electric energy (due to its physical properties) has greater controllability than the thermal energy. This characteristic affects the economic attractiveness of the heat supply system. Electricity can be more accurately accounted and distributed therefore the electric heat supply makes possible to achieve an exact ratio between the consumed and produced energy. An expected economic effect determines by the savings costs at the heat supple cycle up to $30 \%$.

c) Compactness. Electric networks, as well as electric heating systems, are much more compact (and cheaper) than other heating networks and systems. This is especially important in large cities due to great buildings density and the increasing number of cars requiring parking spaces. [20]. Introduction of electric heat supply opens the possibility of wide using underground spaces for the needs of the city.

d) Efficiency. According to the nature of the electricity the process of energy transfer it is possible to provide with the efficiency index exceeding the same index when we are dealing with other heat transfer agents.

\section{Conclusions}

All of the above confirms that the Russian heat supply system needs radical changes. Based on the experience of other countries and adapting it to the conditions and opportunities of domestic energy, it can be assumed that the use of electricity as a heat transfer agent will open new economic prospects in the heat power industry. It can reorient the heat power engineering to effective functioning. It allows us to conclude that the implementation of new types of heat power engineering is perspective from the positions of economic development of the Fuel Energy Complex and the national economy as a whole.

\section{References}

1. BP Statistical Review of World Energy. URL: https://www.bp.com/content/dam/bp-country/de_ch/PDF/bpstatistical-review-of-world-energy-2017-full-report.pdf

2. A. Makarov, L. Grigoreva, T. Mitrova, Forecast of the development of the energy sector of the world and Russia. 196 (2016)

3. A. Galkina, D. Grushevenko, E. Grushevenko, V Kulagin, I. Mironova, St. Petersburg Polytechnic University Journal of Engineering Science and Technology. 63 (1) (2015)

4. A. Kolpakov, Scientific works of IEF RAS. 103 (2012)

5. T. Kharlamova, K. Osipova, St. Petersburg economic J. 141 (1) (2018)

6. V. Okorokov, R. Okorokov, Vestnik IGEU J. 73 (6) (2015)

7. V. Dzhangirov, N. Lelyushkin, V. Maslov, Power and Industry of Russia J. 30 (1) (2010)

8. A. Trinchenko, A. Paramonov, IOP Conference Series: Earth and Environmental Science. 90(1) 012094 (2017) 
9. A. Kharlamov, E. Efanova, Problems of modern economics. 86 (2) (2016)

10. B. Revich, Studies on Russian Economic Development. 89 (4) (2010)

11. O. Dyomina, Spatial Economics. 41 (4) (2016)

12. A. Nekrasov, Y. Sinyak, S. Voronina, V. Semikashev, Studies on Russian Economic Development. 35 (1) (2011)

13. N. Kuznecova, Science area. 68 (1) (2012)

14. I. Bashmakov, The analysis of the main trends in the development of heat supply systems in Russia and abroad URL: http://www.cenef.ru/art_11212_119_node2.html

15. R. Okorokov, A. Timofeeva, A. MATEC Web of Conferences170,03004 (2018)

16. I. Anikina, V. Sergeyev, N. Amosov, M. Luchko, International Journal of Hydrogen Energy42(1) (2017)

17. E. Fachrislamova, C. Chernov, Bulletin of ZabGU. 124 (4) (2016)

18. T. Burtseva, V. Aleshnikova, M. Dubovik, K. Naidenkova, N. Kovalchuk, N. Repetskaya, O. Kuzmina, A. Surkov, O. Bershadskaya, A. Smirennikova, IJESE. 8186 (11) 2016

19. A. Ayrapetova, The modern aspects of economy. 13 (9) (2015)

20. T. Kharlamova SPbWOSCE-2017. URL: https://www.matec-conferences.org/ articles/matecconf/abs/2018/29/ contents/contents.html (2017). 